\title{
Abordagem Interdisciplinar em Educação Ambiental
}

\section{Interdisciplinary Approach to Environmental Education}

Fátima Helena da Fonseca Miranda ${ }^{1}$ José Arlindo Miranda ${ }^{2}$

Rosana Ravaglia ${ }^{3}$

\begin{abstract}
Resumo
Faz parte dos princípios da Educação Ambiental o enfoque do pluralismo de idéias pedagógicas na perspectiva da inter, multi e transdisciplinar; posto a complexidade desta temática, o presente artigo apresenta o enfoque de interdisciplinaridade em educação ambiental referido por diferentes autores. São descritos os desafios de se trabalhar a Educação Ambiental na educação formal sob a ótica interdisciplinar em consonância com as Diretrizes da Política Nacional de Educação Ambiental (Lei 9795/99) Reafirma a importância da integração do conhecimento e da ação ambiental no campo da educação.
\end{abstract}

Pavavras-chave: educação ambiental, interdisciplinaridade, educação.

\section{Abstract}

Part of the principles of environmental education the focus of educational pluralism of ideas in terms of inter, multi and transdisciplinary; put the complexity of this issue, this article presents the focus of interdisciplinary environmental education mentioned by different authors. Describes the challenges of working in environmental education in formal education in the interdisciplinary perspective in line with the Guidelines of the National Policy for Environmental Education (Law 9795/99) Reaffirms the importance of the knowledge and action in the field of environmental education.

Keywords: environmental education, interdisciplinary, Education.

\footnotetext{
${ }^{1}$ Graduação em História, pós-graduação em História do Brasil, Ecoturismo Interpretação e Educação Ambiental, Mestranda em Ensino em Ciências da Saúde e do Meio Ambiente do UNIFOA - Centro Universitário de Volta Redonda. RJ. Professora de História da Rede Pública do Município de ResendeRJ. Membro do CREAR- Centro de Referência de Educaçâo Ambiental de Resende, RJ.

${ }^{2}$ Graduação em Administração e Direito, pós-graduação em Sistemas Públicos Municipais, Mestrando em Ensino em Ciências da Saúde e do Meio Ambiente do UNIFOA - Centro Universitário de Volta Redonda, RJ.

${ }^{3}$ Doutorado e Mestrado em Engenharia Metalúrgica PUC/RJ. Professora da Graduação e Mestrado do UNIFOA - Centro Universitário de Volta Redonda, RJ
} 


\section{INTRODUÇÃO}

Os graves problemas do planeta, gerados pelo uso indiscriminado dos seus recursos produz consequências e implicaçôes na qualidade de vida de seus habitantes. Segundo (Reigota, 2001 pág 12), "Os problemas ambientais foram criados por homens e mulheres e deles virão as soluçóes. Estas náo serão obras de gênios, de políticos ou tecnocratas, mas sim de cidadãos e cidadãs".

É nesse sentido que (Dias 2003, pág. 148), afirma: “O fator mais importante que contribui para a especificidade da Educação Ambiental é, sem dúvida, sua ênfase na resolução de problemas práticos que afetam o meio ambiente humano." E ainda acrescenta: "disso deriva outra característica fundamental da Educação Ambiental, a abordagem interdisciplinar, que considera a complexidade dos problemas ambientais e a multiplicidade dos fatores ligados a eles".

Nesse contexto um dos princípios básicos da Educação Ambiental apresentado pela Política Nacional de Educação Ambiental é o pluralismo de idéias pedagógicas na perspectiva da inter, multi e transdisicplinar. O presente estudo pautouse na abordagem interdisciplinar em educação ambiental.

Considerando-se que um dos grandes desafios da Educação Ambiental é sua a inserção na educação formal sob a ótica interdisciplinar em consonância com as Diretrizes da Política Nacional de Educação Ambiental (Lei 9795/99), como superar este desafio?

Reconhece-se que, para superá-lo, são necessários esforços de muitas áreas.

"Aos educadores cabem a responsabilidade de acordar o aluno para o bom senso de descobrir dentro de si a autoconfiança e potencialidade para o exercício de sua cidadania, desencadeando posturas e atuaçóes mediante as dificuldades sócio ambientais. Os ensinamentos e práticas pedagógicas para os novos paradigmas da educação exigem conhecimentos metodológicos específicos, bem como novas relaçôes com os conteúdos holísticos”( FLICK).

\section{EDUCAÇÃO E INTERDISCIPLINARIDADE}

Sabemos que a educação tem por missão, possibilitar ao educando tomar consciência de sua realidade de forma crítica, assegurando-lhe formação indispensável para o exercício da cidadania. Assim ao longo da vida a educação deve basear-se nos pilares: aprender a conhecer, aprender a fazer, aprender a viver juntos, aprender a ser. A educação deve tornar-se assim, uma construção contínua de cada pessoa humana, do seu saber de suas aptidóes, de sua capacidade de discernir e agir.

\begin{abstract}
"Todo desenvolvimento verdadeiramente humano significa desenvolvimento em conjunto das autonomias individuais, das participações comunitárias e do sentimento de pertencer à espécie humana. Compreender o humano é compreender sua unidade na diversidade, sua diversidade na unidade. É preciso conceber a unidade do múltiplo, a multiplicidade do uno" (MORIN, 2002 pág. 55).
\end{abstract}

Assim educação deverá ilustrar este princípio de unidade/ diversidade em todas as esferas. Conforme (Perrota, 2000 pág. 100), “o conhecimento é considerado processo e não um dado adquirido, pronto, completo. Pelo contrário, é sempre um devir”.

O desenvolvimento científico e os avanços tecnológicos, no século $\mathrm{XX}$, constataram que o sujeito pesquisador interfere no objeto pesquisado, assim não há neutralidade no conhecimento, a consciência da realidade se constrói num processo de interpenetraçáo dos diferentes campos do saber.

Pensar a interdisciplinaridade enquanto processo de integração recíproca entre várias disciplinas e campos de conhecimento é sem dúvida, uma tarefa que demanda, de nossa parte, um grande esforço no rompimento de uma série de obstáculos ligados a uma racionalidade extremamente positivista da sociedade industrializada. Cabe-nos voltar para uma visão integrada do meio em que vivemos.

\footnotetext{
"portanto, o desafio que é apresentado à educação, a fim de que contribua para formação de pessoas capazes de se defrontarem com os problemas do seu ambiente cultural e natural, consiste em que se apresente como uma ação educativa dinâmica e dialética, visando desenvolver entre seus participantes a consciência da realidade humana e social, da qual a escola faz parte mediante uma perspectiva globalizadora” (LUCK 2003, pág. 31 e 32)
}

Face a essas idéias, torna-se necessário repensar a produção e a sistematização do conhecimento fora das posturas científic4as dogmáticas, no sentido de inseri-las num contexto de totalidade. $\mathrm{O}$ enfoque interdisciplinar na educaçáo apresenta-se como superação da fragmentação do conhecimento.

"para fazer face aos desafios da nova situação civilizacional, ganha força a idéia de uma abordagem interdisciplinar nos sistemas formais da educação, visto que o paradigma teórico-medológico oriundo do cartesianismo perdeu sua eficácia, já que não é capaz de resgatar a unidade do saber. (SANTOS E PEREIRA 1999, pág. 150).

A educação precisa ser praticada interdisciplinarmente, porém sabemos que o sistema escolar, da forma como se encontra não favorece o trabalho em conjunto. Tudo é 
compartimentado. Conforme (Dias, 1993 Pág), "as universidades são divididas em departamentos, o conhecimento é dividido em disciplinas, e assim por diante. Dividimos tudo e perdemos a noção do todo". Assim, as dificuldades que surgirem na prática interdisciplinar serão normais. Entretanto, precisamos criar, ousar.

A necessidade de romper com a tendência fragmentadora e desarticulada do processo do conhecimento, justifica-se pela compreensão da importância da interação e transformação recíprocas entre as diferentes áreas do saber. A inter relação entre as diferentes disciplinas favorece o enriquecimento ao abordar um tema.

\begin{abstract}
'Interdisciplinaridade é o processo que envolve a integração e engajamento de educadores num trabalho em conjunto, de interação das disciplinas do currículo escolar entre si com a realidade, de modo a superar a fragmentação do ensino, objetivando a formação integral dos alunos, a fim de que possam exercer criticamente a cidadania, mediante uma visão global de um mundo e serem capazes de enfrentar os problemas complexos, amplos e globais da realidade atual” (LUCK 2003, pág. 64).
\end{abstract}

A interdisciplinaridade e a contextualização devem formar o eixo organizador dos currículos. Conectar os inúmeros conhecimentos e suas aplicaçôes deve ser a proposta de todo professor. Não é possível esperar soluçóes salvadoras e de grande porte, mas encara a educação numa perspectiva de conflito, de inquietação pessoal que levará a busca da mudança e de um novo paradigma educacional. $\mathrm{O}$ engajamento de professores num trabalho conjunto de integração das disciplinas entre si, conectando os inúmeros conhecimentos, transcende o simples ensinar porque terá um sentido mais amplo, onde o professor e o aluno passaráo a ser vistos como parte de uma grande teia de relaçóes com o mundo, e sendo parte deste mundo não poderão mais ser vistos de forma fragmentada.

A interdisciplinaridade enquanto aspiração emergente de superação da racionalidade científica positivista, aparece como entendimento de uma nova forma de institucionalizar a produção do conhecimento nos espaços da pesquisa, na articulação de novos paradigmas curriculares e na comunicação do processo perceber as várias disciplinas; nas determinaçóes do domínio das investigaçôes, na constituição das linguagens partilhadas, nas pluralidades dos saberes, nas possibilidades de trocas de experiências e nos modos de realização da parceria.

Portanto, trabalhar a interdisciplinaridade não significa negar as especialidades e objetividade de cada ciência, é uma interação ativa entre as diferentes disciplinas promovendo o intercâmbio e o enriquecimento na abordagem de um tema. A interdisciplinaridade deve respeitar o território de cada campo do conhecimento, bem como distinguir os pontos que os unem e que os diferenciam. Essa é a condição necessária para detectar as áreas onde se possam estabelecer as conexóes possíveis.

\section{ENFOQUE INTERDISCIPLINAR EM EDUCA- ÇÃO AMBIENTAL}

Apresenta (Dias 2003 pág 98), que oriunda da Conferência Intergovernamental da Educação Ambiental de Tbilisi (1977), a Educação Ambiental passou a ter a seguinte definição: "dimensão dada ao conteúdo e à prática da educação, orientada para a resolução dos problemas concretos do meio ambiente através de enfoques interdisciplinares e de uma participação ativa e responsável de cada indivíduo e da coletividade."

A Conferência Intergovernamental sobre educação Ambiental de Tbilisi propôs como um dos princípios básicos da Educação Ambiental: aplicar um enfoque interdisciplinar, aproveitando o conteúdo específico de cada disciplina, de modo que se adquira uma perspectiva global e equilibrada.

A cerca deste princípio (Dias, 2003 pág. 117): afirma “pela própria natureza do ambiente, dadas as suas múltiplas interaçóes de fundo ecológico, político, social, econômico, ético, cultural, científico e tecnológico, não se poderia tratar o assunto em uma única disciplina.” Uma importante contribuição neste aspecto está contemplada nos Parâmetros Curriculares Nacionais através da transversalidade dos temas, cujo meio ambiente é um deles.

Para tentar colocar em prática as recomendaçóes a da Conferência de Tbilisi o Brasil aprovou e sancionou A Lei 9795/99 Política Nacional de Educação Ambiental estabelecendo a educação ambiental como um componente essencial e permanente da educação nacional, devendo estar presente, de forma articulada, em todos os níveis e modalidades do processo educativo, em caráter formal e não-formal que deverá ser desenvolvida como uma prática educativa integrada, contínua envolvendo todos os professores. $\mathrm{Na}$ verdade, a abordagem interdisciplinar defende a superação da fragmentação do saber.

A lei Federal no 9795, de 27 de abril de 1999, que instituiu a "Política Nacional de Educação Ambiental" trata a questấo da importância do enfoque interdisciplinar como essencial para o desenvolvimento da educação ambiental no Brasil:

A abordagem interdisciplinar das questóes ambientais implica em utilizar a contribuição das várias disciplinas (conteúdo e método) para se construir a compreensão e explicação do problema tratado e desse modo, superar a compartimentação. Implica, também, em envolver as populaçóes e valorizar seus conhecimentos. 
"O enfoque interdisciplinar preconiza a ação das diversas disciplinas em torno de temas específicos. Assim, torna-se imperativa a cooperação/ interação entre todas as disciplinas. Ultimamente, tem sido, muito grande as contribuiçôes por parte das artes, dado o seu grande potencial de trabalhar com sensibilização, elemento essencial para comunicar-se efetivamente. Antes, a EA ficava restrita à área de Ciências ou Biologia, o que foi um erro. Precisamos praticar a EA de modo que ela possa oferecer uma perspectiva global da realidade e não uma perspectiva científica e biológica apenas. São importantes os aspectos sociais, históricos, geográficos, matemáticos, de línguas, da expressão corporal, da filosofia, etc.” (DIAS pág 117).

O enfoque interdisciplinar em educação ambiental também é comentado por (Reigota 2001, pág. 39) "A educação ambiental esta também muito ligada ao método interdisciplinar. Esse método, no entanto , é compreendido e aplicado das mais diversas formas." E ainda acrescenta: (pág. 40) "além de uma compreensão mais global sobre o tema , esse método pode proporcionar intercâmbio de experiências entre professores e alunos e envolver toda comunidade escolar e extra-escolar".

No ensino fundamental de $6^{\circ}$ ao $9^{\circ}$, é grande a dificuldade de obter uma visão mais global da realidade, uma vez que geralmente o conhecimento é apresentado para os alunos de forma fragmentada pelas disciplinas que compóem a grade curricular.

Entretanto, a formulaçáo do projeto educacional da escola, por meio da discussão, decisão e encaminhamentos conjuntos, com atribuição de responsabilidades, possibilita superar o fracionamento do saber: divergências de interesses, as várias formaçôes profissionais e as diferentes escalas de valores, por terem que se articular na efetivaçáo de projeto pedagógico, pode contribuir para a construção desse espaço coletivo. Além disso, viabiliza-se o diálogo entre docentes, e a atuação conjunta, em que será possível a construção de atitudes e valores. Atividades como realizaçáo de excursóes, criaçáo de viveiros de mudas e hortas comunitárias, participação em debates, etc.., possibilitam um trabalho mais integrado, com maior envolvimento dos alunos, e a participação no espaço social mais amplo, no que se refere à solução dos problemas ambientais.

Para que os alunos construam a visão da globalidade das questōes ambientais é necessário que cada profissional de ensino, mesmo especialista em determinada área do conhecimento, seja um dos agentes da interdisciplinaridade que o tema exige. A riqueza do trabalho será maior se os professores de todas as disciplinas discutirem e, apesar de todo o tipo de dificuldades, encontrarem pontos comuns para desenvolver um trabalho em conjunto. Assim a inter- disciplinaridade procurará a superaçâo da visão fragmentada do conhecimento pelos professores especialistas.

Cada professor deverá contemplar a temática ambiental dentro da especificidade de sua área, contribuindo para que cada aluno tenha uma visão mais integrada do ambiente. Ciências, Geografia e História são áreas já tradicionais na parceria desenvolvendo conteúdos relacionados ao ambiente. Porém, as demais áreas são de fundamental importância na abordagem interdisciplinar dessa temática: Língua Portuguesa poderá trabalhar com textos relacionados aos valores propostos pela Educação Ambiental; Arte através das diversificadas expressóes teatro, música, sensibilizando para um ambiente de qualidade; Matemática propondointerpretaçấo de dados estimulando a aquisição de novos hábitos de desenvolvimento sustentável como economia, racionacinalização , reutilizaçấo e reciclagem dos recursos naturais; Educação Física ajudando na compreensão da relação do corpo com o ambiente. Todas as áreas são importantes, pois permitem conduzir os alunos a construçáo do conhecimento sobre o meio ambiente ajudando-os a manifestar seu pensamento e expressá-los de forma mais consciente.

\footnotetext{
“a Educação Ambiental não deve priorizar a transmissão de conceitos específicos da biologia ou da geografia. No entanto, alguns conceitos básicos, tais como ecossistema, hábitat, nicho ecológico, fotossíntese, cadeia alimentar, cadeia de energia etc., devem ser compreendidos pelos alunos, e não decorados e repetidos automaticamente por eles. Os conceitos acima citados, entre outros, têm como função fazer a ligação entre a ciência e os problemas ambientais cotidianos. Dessa forma, cada disciplina tem sua contribuição a dar nas atividades de educaçáo ambiental, envolvendo os professores de biologia, português, educação artística , história entre outros. (REIGOTA 2001 pág. 36).
}

O Pcn, tema transversal meio ambiente: pág. 194 propôe :"É interessante, ainda que se destaque o ambiente como parte do contexto geral as relaçóes ser humano/ser humano e ser humano/natureza, em todas as áreas de ensino na abordagem dos diferentes conteúdos:".

"A realização conjunta das atividades em diferentes áreas de estudo ou disciplinas e do esforço coletivo do corpo dirigente, do corpo docente e corpo discente associados à família e à comunidade resultará em um trabalho interdisciplinar para o desenvolvimento da Educação Ambiental na escola" (MATTOS).

Assim compreendida, a Educação Ambiental torna-se uma alternativa de ensino oferecendo, à escola, uma grande chance de renovaçáo. 
A respeito da contribuição interdisciplinaridade na Educação ambiental Coimbra recomenda: "A Educação Ambiental e a Interdisciplinaridade, pode e deve realmente Constituir/Construir um motor de Transformação/Libertação pedagógica, aonde, neste sentido, venham a agir como um integrador de criatividade.

\section{DESAFIOS DE SE TRABALHAR A INTERDISCI- PLINARIDADE EM EDUCAÇÁO AMBIENTAL}

No que se refere aos desafios da Educaçáo Ambiental em ser tratada sob a ótica interdisciplinar podemos destacar alguns, entre eles o descompasso entre teorias, metodologias, pedagogias e aplicabilidades; a não incorporação da dimensão ambiental na formação das licenciaturas, a não adequação à lei 9597/99; a falta de compromisso político com relação a Educação ambiental por grande parte dos governantes.

As diretrizes da Conferência de Tbilisi,1977 já reforçavam este aspecto, na medida em que apontava para que os estabelecimento de educação e de formação pudessem criar programas de educação ambiental para facilitar aos futuros professores uma formação ambiental apropriada à zona urbana ou rural; e tomar medidas necessárias para que a formação em Educação Ambiental, e esta estivesse ao alcance de todos os professores. Contudo, o que se constata é que apenas aos professores são atribuídas essas tarefas e grande parte não se compromete, pois percebem que gestores, dirigentes autoridades competentes não cumprem as recomendaçóes que lhes são atribuídas.

Na proposição da lei (9795/99) a dimensão ambiental deve constar dos currículos de formação de professores, em todos os níveis e em todas as disciplinas, e nos cursos de pósgraduação, extensão e nas áreas voltadas ao aspecto metodológico da educação ambiental, quando se fizer necessário, é facultada a criação de disciplina específica. E ainda acrescenta: os professores em atividade devem receber formação complementar em suas áreas de atuação, com o propósito de atender adequadamente ao cumprimento dos princípios e objetivos da Política Nacional de Educação Ambiental.

Percebe-se que um dos grandes desafios para a inserçáo da Educação Ambiental nas escolas é justamente a falta de capacitação dos professores, no que diz respeito às questóes ambientais, como reverter essa situação?

Pelas recomendaçôes da lei a formação contemplaria as diversas áreas de atuação, com profissionais mais bem preparados, para tratarem os temas ambientais nos ensinos fundamental e médio e também no ensino superior. Estes teriam um maior interesse em correlacionar as suas disciplinas com a Educação Ambiental, já que isso não é feito normalmente.
No entanto alguns justificam que a não utilização dessa prática decorre de seu despreparo, da falta de tempo, e da escola não possuir uma prática constante de execução das novas propostas e de compromisso com projetos de uma forma geral, muito menos quando direcionado à Educação Ambiental.

Cumpre ressaltar que a escola ainda não se adequou, de forma suficiente, para desenvolver projetos interdisciplinares conforme sugere a lei 9795/99.

Educação Ambiental na maioria das vezes é desenvolvida nas escolas de forma ainda tímida, algumas atividades são abordadas de forma pontuais sugerindo "à preservação do ambiente". No entendimento de Mattos: A escola precisa oferecer condiçôes de estudo e aperfeiçoamento, promovendo, entre outras açóes, seminários e cursos com especialistas na área. A forma holística pela qual deveria ser tratada a Educação Ambiental fica ausente ou, ainda, sem ser compreendida pela escola e pelos educadores.

$\mathrm{Na}$ verdade, a abordagem interdisciplinar defende a superação da fragmentação do saber. A realização conjunta das atividades em diferentes áreas de estudo ou disciplinas e do esforço coletivo do corpo dirigente, do corpo docente e corpo discente associados à família e à comunidade resultará em um trabalho interdisciplinar para o desenvolvimento da Educação Ambiental na escola.

A Educação Ambiental assim compreendida é uma alternativa de ensino que oferece, à escola, uma grande chance de renovação.

Nota-se que a contribuição dos teóricos, particularmente os que se referem ao estudo das representaçôes sociais de meio ambiente e de percepção ambiental, oferecem fundamentos para experiências diversas em educação ambiental a nível escolar influenciam significativamente na produção de trabalhos de pesquisa com alunos e professores da educação básica ou do ensino superior, como forma de aprofundar a compreensão da prática educativa ambiental.

Passados dez anos da promulgação da lei 9795/ 99 de 27 de abril de 1999, intitulada Política Nacional de Educação Ambiental pode-se afirmar que foi sem dúvida uma conquista política construída por centenas de ambientalistas conhecidos e anônimos, funcionários do

Ibama e Ministério do Meio Ambiente e da Educação, dirigentes de Ongs e alguns políticos comprometidos com a causa ambiental.Louvem-se esses esforços. No entanto, sem apresentar as fontes específicas de recursos para sua implementaçáo, pois o artigo que tratava desta questão foi vetado pelo Poder Executivo. A Lei contempla inovaçóes em diversos aspectos, trazendo as incumbências de cada ator social Poder Público, instituiçóes educativas, empresas, sociedade etc., além dos princípios e objetivos da Educação Ambiental.

Conforme a Lei, as atividades vinculadas à Política Nacional de Educação Ambiental devem ser desenvolvidas na 
educação em geral e na educação escolar através: da capacitação de recursos humanos, do desenvolvimento de estudos e pesquisas, da produçáo de material educativo e do acompanhamento e avaliação. Lamenta-se a falta de compromisso e valor dado à educação ambiental pela grande maioria dos dirigentes políticos municipais, estaduais e federais de nosso país.

"as Secretaria Estaduais de Educação, nas suas infinitas metamorfoses, sempre à deriva das oscilações políticas, não tem orientaçóes duradouras. Mudam os políticos, mudam os secretários, mudam os diretores, mudam as idéias, mudam os planos, os quatro anos acabam e tudo está para começar. Daí um novo mandato e tudo se repete. A situação e fractual” (Dias,2003 pág17-18).

Diante desse contexto (Dias 2003 pág 19) acrescenta "Reconhece-se que para a reversão dessa condição são necessários esforços de muitas áreas, além da educacional” Necessita-se sair da condição de pensante e passar para a de atuante.

No entendimento de Flick: A Educação Ambiental tem papel preponderante e relevante "tanto em relação às propostas de gestáo educacional e do meio ambiente, quanto em políticas públicas e conhecimentos inerentes à temática, na releitura, no repensar das atitudes de ordem e valores individuais e coletivas". Precisa-se sair do campo da informação para a sensibilização em todos os níveis. E o que propóe (Dias 2003, pág 126) "Os processos de sensibilização tem o potencial de preparar pessoas para mudanças".

\section{CONSIDERAÇÓES FINAIS}

O processo educacional, está em construção, aos poucos superando erros, somando esforços para assumir uma atitude interdisciplinar, busca-se novos caminhos para uma educação mais significativa. Percebe-se que os referenciais teóricos oferecem suporte para que cada educador/a possa incorporar em suas práticas a abordagem interdisciplinar em Educação Ambiental.

A compreensão acerca do meio ambiente encontra-se em processo de mudança. Daí que o Brasil se destacou dentre os países da América Latina como o primeiro a promulgar uma lei de Política Nacional de Educação Ambiental, a lei 9795/ 99 de 27 de abril de 1999. Mesmo com este amparo legal, entendemos que será necessário um compromisso dos gestores das instituiçóes educacionais públicas e privadas, dos sistemas de ensino em desenvolver instrumentos e metodologias visando a incorporação da dimensão ambiental, de forma interdisciplinar nos diferentes níveis e modalidades do ensino formal.

Face à magnitude dessa tarefa a Educação Ambiental formal deve promover uma mudança de comportamentos contribuindo na transição para o desenvolvimento sustentável.

\section{REFERÊNCIAS BIBLIOGRÁFICAS}

COIMBRA, Audrey de Souza . Interdisciplinaridade e Educação Ambiental: integrando seus princípios necessários. Revista. Eletrônica do Mestrado. Educação. Ambiental. ISSN 1517-1256, Volume 14, Janeiro a junho de 2005. Acesso em 22 de maio de 2009.

DIAS. Genebaldo Freire. Educaçáo ambiental: princípios e práticas. 8.ed. São Paulo: Gaia, 2003. 551p.

Atividades interdisciplinares de educaçáo ambiental. São Paulo: Global/Gaia.1994. 137p.

FLICK Maria Esther Pereira CENED - Centro Nacional de Educação Ambiental: Educaçáo Ambiental e formaçáo de professores. Disponível em www.cenedcursos.com.br . Acesso em 25 de junho de 2009.

LÜCK, Heloísa. Pedagogia interdisciplinar: fundamentos teórico-metodológicos. 11 ed. Petrópolis, RJ: Vozes, 2003.

MATTOS Suzi. A Educaçáo Ambiental na escola: Teoria X Prática sob o ponto de vista interdisciplinar. II Fórum Ambiental da Alta Paulista 2528 de outubro de 2006. wwwamigosdanatureza.org.br acesso em 20 maio de 2009

MORIN, Edgar. Os sete saberes necessários à educaçáo do futuro. 6 ed. São Paulo: Cortez, 2002.

PERROTA, Mari-Pepa. Novos fundamentos para uma didática crítica. Rio de Janeiro: 7 Letras, 2000.

REIGOTA, Marcos. O que é educação ambiental. São Paulo: Brasiliense, 2001.63p.

SANTOS, José Messias dos : PEREIRA, Adilson. Cosmovisão, epistemologia e educaçáo: uma compreensáo holística da realidade. 2 ed. Rio de Janeiro: Editora Gama Filho, 1999.

<hptt: // www.mec.gv.br/sef/ambiental/pnea.shtm> Acesso em 05 mar. De 2005.

Endereço para Correspondência:

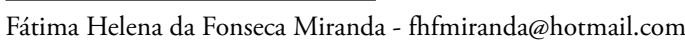

Rua Antônio Veloso Júnior, 55 - Edifício Dona Cotinha, apto. 304 Campos Elíseos - Resende -RJ

CEP: 27541-200 